\title{
5 \\ DIREITOS HUMANOS NO CONTEXTO DAS REGRESSÕES ULTRANEOLIBERAIS NO BRASIL ${ }^{*}$
}

Silene de Moraes Freire

Vânia Morales Sierra

"[...] Em vão percorremos volumes, viajamos e nos colorimos. A hora pressentida esmigalha-se em pó na rua. Os homens pedem carne. Fogo. Sapatos. As leis não bastam. Os lírios não nascem da lei. Meu nome é tumulto e escreve-se na pedra [...]."

(ANDRADE, Carlos Drummond. Nosso tempo. In: A Rosa do Povo, 1945)

\section{Introdução}

0 presente estudo visa contribuir para o entendimento da necessária luta em defesa dos direitos humanos no atual contexto, diante de um conjunto de regressões guiadas pela implementação de uma agenda ultraneoliberal que aniquila uma série de direitos conquistados historicamente pela classe trabalhadora. Nossa intenção é lembrar que é preciso refinar a análise histórica e teórica imprescindível à orientação da ação política. Desta forma objetivamos realizar uma breve análise dos direitos humanos no Brasil, destacando sua relação não casual com os direitos sociais e os limites impostos aos mesmos pelas políticas de vigilância e controle, que aprofundam as subordinações ao capital justificadas por "razões" do Estado, fundamentando políticas cada vez mais punitivas.

Cabe lembrar que o ordenamento jurídico é sempre sustentado por um corpo que lhe confere legitimação, pela necessidade de controlar os problemas provenientes dos antagonismos de classe, com vistas à administração dos conflitos por meio de um poder exercido por um terceiro imparcial, o Estado. Neste sentido, teria o direito positivo uma função de socialização em decorrência de sua capacidade de disciplinar os indivíduos, mediante a punição independente de classe, gênero, cor, raça, etnia.

"DOI - 10.29388/978-65-86678-42-0-0-f.125-146 
A criminologia crítica define o direito como um instrumento de controle sobre a classe trabalhadora, cujas mudanças decorrem da relação entre mercado, força de trabalho e punição. Desse modo, a pena seria mais ou menos rigorosa não pela intensidade com que fere a consciência coletiva, mas em resposta à necessidade do mercado de trabalho de dispor da força de trabalho. Por outro lado, a sua complexificação acompanha a sua expansão, uma vez que regula a mercadorização de diversas áreas, como educação, saúde, assistência etc., ampliando o número de regulamentações e aumentando, portanto, crimes e punições que lhes são correspondentes.

De certo modo, o capitalismo é o sistema político e econômico que mais crimes produz. Funciona como uma máquina de produção de regulamentações, crimes e punições. Para cada inovação, uma legislação de proteção de propriedade é criada, cuja violação se torna crime. Desse modo, a sociedade vai multiplicando as grades dessa "jaula de ferro" weberiana, que vai absorvendo todas as esferas da vida humana. É de dentro dessa jaula que os direitos humanos se insurgem, como um grito contido e sufocado de pessoas que recusam a sujeição. Neste sentido, os direitos humanos se tornam a "arma" da sociedade contra o Estado, o recurso dos "fracos" contra os fortes, possibilitando uma abertura ao questionamento dessa legitimidade de fachada derivada dos modelos jurídicos que nos governam.

Neste capítulo, os direitos humanos são pensados a partir de uma abordagem crítica guiada mais uma vez pelo desejo de suspender as "ilusões jurídicas" para retomar nos direitos humanos o seu potencial de luta contra o capital, o "moinho satânico" da sociedade. Desta forma, o que definimos como barbárie representa não apenas uma crise civilizatória como também o recuo e a destruição de garantias concernentes aos direitos humanos.

0 texto está organizado em três seções. Primeiramente será discutida a institucionalização dos direitos humanos no Brasil. Em seguida, o contexto da barbárie ultraneoliberal será analisado como um impedimento à efetivação dos direitos. Por fim, a análise se concentrará sobre a emergência do conservadorismo e a derrocada dos direitos humanos, no contexto de afirmação da política ultraneoliberal.

\section{A Institucionalização dos Direitos Humanos no Brasil}

Com 72 anos completados em 2020, a Declaração Universal dos Direitos Humanos, mais importante marco "universalizador" que coroou a militância dos direitos humanos do pós-Segunda Guerra Mundial, continua 
evidenciando que a disputa do tema parece longe de ser encerrada. Conforme observou José Damião Trindade (2006), ao resgatar a "História social dos direitos humanos", o motivo da expressão Direitos Humanos ter se tornado tão maleável, complacente e moldável pelos mais inesperados personagens sempre foi uma das características do debate e continua sendo frequente no século XXI. Segundo o autor, o uso diferente por Canalhas e Anjos estaria exatamente a indicar a complexidade deste tema. Para ele, o fato de que diferentes figuras políticas se apropriaram da linguagem dos direitos humanos para respaldarem esquemas de ordem social, até mesmo com um caráter ditatorial, colabora para aumentar a complexidade que envolve o debate ${ }^{1}$.

Apesar do tempo de existência da Declaração Universal dos Direitos Humanos e da complexidade do debate, no Brasil a problematização acerca dos Direitos Humanos ainda é muito incipiente, mesmo tendo sido nos últimos anos um tema bastante abordado nas agendas dos movimentos sociais e dos governos do século XXI. A partir de 2019 é nítido um retrocesso na agenda capaz de assegurar esses direitos. Ou melhor, é evidente a utilização desta pauta por Canalhas.

Conforme Freire mencionou em estudos anteriores (2009, 2011, 2014 e 2020), a questão das violações e a descoberta de uma nova postura na valorização dos direitos humanos não encontrou, em nossa latitude, a mesma força que em outros países. É certo que esta importância foi diferenciada de país para país. A agenda de defesa e garantia dos direitos humanos na América Latina, por exemplo, foi tardiamente ativada podendo ser percebida mais especialmente na luta contra as ditaduras que abalaram a vida latino-americana. Vale lembrar que o tema da violação dos Direitos Humanos foi um dos pontos mais importantes da pauta política no período de transição para democracia em diferentes países da região ${ }^{2}$. 0 Brasil também fez parte desta luta tardia. Assim, a defesa dos direitos humanos no Brasil remete diretamente ao terrorismo de Estado do final do século XX relacionado à questão da ditadura militar, "que dizimou e encarcerou centenas de vidas (dos sujeitos de distintos projetos societários que lutavam

\footnotetext{
${ }^{1}$ Um exemplo verídico foi a trajetória do nazismo na sociedade Germânica, tendo como ícone a pessoa de Hitler.

${ }^{2}$ Não é um tema específico da América Latina a questão dos direitos humanos e o tratamento dos conflitos posteriores à liberalização e democratização dos regimes autoritários. A mesma situação apresentou-se em países como Espanha, Portugal e Grécia, quando do final de períodos de autoritarismo que, no caso português e espanhol, duraram mais de três décadas.
} 
por um país democrático) nos duros e longos 21 anos em que vigorou" (FREIRE, 2014, p. 16).

A característica principal do retorno à democracia em nosso país foi a transição "pelo alto". Ou seja, o fim do regime autoritário no Brasil foi viabilizado através de uma "transição negociada para a democracia". Desde a metade dos anos 70 preparava-se o processo da "distensão" lenta e gradual para a "Abertura". Como observou Freire, as violações mais graves cometidas pela ditadura militar no Brasil ocorreram no início dos anos 70, no Governo Médici que ficou conhecido como os "anos de chumbo" 3 do regime. A linha dura entre os militares foi contida no Governo Geisel (1974-1979), diminuindo e mudando o caráter das formas de repressão (Ibidem).

Uma década e meia após o Golpe de 1964, ou seja, em meados do ano de 1979, a lei 6.683, denominada Lei da Anistia (BRASIL, 1979), concedeu anistia aos que cometeram "crimes políticos ou conexos com este" (art. $1^{\circ}$ ), excetuando os que foram condenados pela prática de crimes de terrorismos, assalto, sequestro e atentado pessoal (par. 2o). A Lei de Anistia de 1979 tinha dois objetivos: permitir a reincorporação à vida política dos exilados, cassados e presos políticos e tentar anular na raiz qualquer possibilidade de discussão acerca de punições a autoridades envolvidas em atos de terrorismo de Estado - tortura, assassinatos, etc. Mesmo diante das inúmeras denúncias realizadas pelos movimentos sociais sobre os sequestros, as torturas e os assassinatos praticados pelos órgãos de repressão, impossível negar que a anistia pactuada não foi ampla, nem geral, nem irrestrita. Ao contrário, foi limitada e superficial.

Segundo Almeida (2004, p. 43),

a) a sua abrangência foi reduzida à época da promulgação da Lei (15 de agosto de 1979), de forma que a Lei da Anistia buscou instituir o sentido de identidade perfeita entre o "perdão oficial" às práticas prenhes de resistência e lutas e o fim dos atos que o ensejaram; b) a interpretação hegemônica, ensejada pela definição de "crimes conexos", isto é, "os crimes de qualquer natureza relacionados com crimes políticos ou praticados por motivação política" (art. 1o, par. 10), segun-

\footnotetext{
${ }^{3}$ Os chamados Anos de Chumbo no Brasil, período mais repressivo da ditadura militar, estenderam-se basicamente do fim de 1968, com a edição do AI-5 em 13 de dezembro daquele ano, até o final do governo Médici, em março de 1974. Alguns analistas do período reservam a expressão "anos de chumbo" especificamente para o governo Médici.
} 
do a qual a Lei abrange a anistia aos torturadores, igualando as práticas de terror do Estado àquelas de resistência a esse terrorismo oficial e institucionalizado - essa interpretação sobrepõe-se, inclusive, ao compromisso internacional assumido pelo Brasil ao ratificar a Convenção Americana de Direitos Humanos, em 1992, que torna imprescritível o crime de tortura.

Em síntese, a lenta e restrita anistia levou 16 anos até que em 4 de dezembro de 1995 a Lei 9.140 declarasse em seu art 1ํo (BRASIL, 1995), que são legalmente reconhecidas como mortas as pessoas que tenham participado, ou tenham sido acusadas de participação, em atividades políticas, no período de 2 de setembro de 1961 a 5 de outubro de 1988, e que, por este motivo, tenham sido detidas por agentes públicos, achando-se, deste então, desaparecidas, sem que delas haja notícias ${ }^{4}$.

Concordamos com Benomar (1993 apud GONZÁLEZ, 2007) quando menciona que o problema da estabilidade das democracias após as transições, nos regimes que praticaram violações de direitos humanos, está relacionado diretamente com uma disputa entre estratégias de punição X estratégias de reconciliação nacional. No Brasil, podemos dizer que mais uma vez, "pelo alto", o que ocorreu foi uma "reconciliação nacional", através de um novo pacto de elites e da fragilidade dos setores atingidos e dos demais movimentos sociais, sobretudo os ligados à defesa dos direitos humanos, para mobilizar a possibilidade de punições aos crimes da ditadura. A transição pactuada afastou da agenda as investigações e julgamentos. Simplesmente não se permitiu que investigações sérias ocorressem, numa espécie de "deixar para traz o passado" e ingressamos numa democracia que até hoje distancia aqueles que se negam esquecer e aqueles que não querem lembrar.

Podemos dizer que a Lei da Anistia foi importante, mas não foi suficiente para resolver impasses que permanecem até os dias atuais. Como observou Almeida (idem, p. 45), o problema está para além de uma questão inerente à lei, pois na verdade está assentado na necessidade das elites em obstaculizarem as possibilidades de "[...] reconstrução e desvendamento de um passado que pulsa insepulto", clamando pelo seu esquecimento e negociando a história através de pactos pelo alto. Desta forma, a transição inconclusa contribuiu para os limites dos direitos humanos em nosso país.

\footnotetext{
${ }^{4}$ A lei traz em anexo uma relação nominal de 136 pessoas e cria uma comissão, com a parti cipação das comissões de familiares, para fazer o levantamento de novos casos não incluídos.
} 
Negados pelas elites, os mesmos emergem para o século XXI através de processos políticos que revelam os limites da democracia no Brasil.

Por isso, não seria exagero mencionar que a ditadura militar, ao aprofundar a cultura política do autoritarismo no Brasil, ampliou o leque da negação dos direitos humanos no país. Sem jogar luzes sobre a tortura do passado, seguiremos longe da tarefa de banir, de vez, a tortura das práticas dos agentes estatais brasileiros e de aprofundar a democracia.

Reconhecer que a realidade brasileira tem demonstrado grandes dificuldades de efetivação dos direitos humanos não significa negar o avanço obtido com o processo de redemocratização, que culminou na Constituição de 1988, considerada o marco na positivação dos direitos humanos. Como destacou Silva (2006, p. 170) foi a Constituição Federal de 1988 que conferiu a primazia dos direitos humanos, ao declará-los principalmente, nos Títulos I (Dos Princípios Fundamentais) e II (Dos Direitos e Garantias Fundamentais) antecedendo a estruturação do Estado. Apenas por questões de registro: é importante ressaltar que, apesar do maior destaque de pioneirismo ser constantemente referido à constituição de 1831 da Bélgica, a primeira constituição, no mundo, que efetivamente subjetivou e positivou os direitos do homem, "dando-lhes concreção jurídica efetiva", foi a constituição do Império do Brasil, de 1824 (Ibidem). No entanto, só com Carta Constitucional de 1988 foi atribuída a "primazia" aos Direitos Humanos no Brasil.

Contudo, "os lírios não nascem da lei", como disse o poeta Carlos Drummond de Andrade ${ }^{5}$ (2000). Se a Constituição federal de 1988 afirmou - com a maior centralidade de nossa história - a primazia dos Direitos Humanos, a realidade a negou. A Constituição de 1988 é um marco da institucionalidade deste debate.

Dentre as ações que caminharam na direção da institucionalização, é importante lembrar o primeiro Programa Nacional dos Direitos Humanos (PNDH) implantado no governo do presidente Fernando Henrique Cardoso, em 1996. 0 Programa representou uma importante abertura à valorização dos direitos humanos na implementação de políticas sociais, afirmando, no conteúdo de seu documento, "[...] atribuir maior ênfase aos direitos civis, ou seja, os que ferem mais diretamente a integridade física e o espaço de cidadania de cada um" sem abandonar uma "compreensão integral e indissociável dos direitos humanos" (BRASIL, 1996, p. 11). 0 texto apresentado pelo PNDH está diretamente articulado aos princípios da Declaração Uni-

\footnotetext{
${ }^{5}$ Frase da poesia "Nosso Tempo" de Carlos Drummond de Andrade, que se encontra no livro “A Rosa do Povo", publicado em 1945. (ANDRADE, 2000)
} 
versal dos Direitos Humanos. Embora os direitos humanos não tenham como se efetivar sem os direitos sociais e políticos, o PNDH defendeu com prioridade os direitos civis em plena consonância com projeto político, social e econômico do primeiro governo de Fernando Henrique Cardoso, cujo maior compromisso era com a garantia dos direitos individuais e com a abertura ao "livre mercado".

Como destaca Netto, as opções do governo estavam em plena conexão com os rumos do novo regime mundial de acumulação do capital, que alterou, de modo específico, o funcionamento do capitalismo.

No Brasil, criavam-se mecanismos políticos-democráticos de regulação da dinâmica do capitalista, no espaço mundial tais mecanismos perdiam vigência e tendiam a ser substituídos, com a legitimação oferecida pela ideologia neoliberal, pela desregulamentação, pela flexibilização e pela privatização - elementos inerentes à mundialização (globalização) operada sob comando do grande capital (NETTO, 1999, p. 77).

Segundo Freire (2014), é neste contexto de nítida opção pelos ajustes neoliberais que o governo FHC acaba por inviabilizar a plena efetivação da Constituição de 1988. Ao ressignificar o papel do Estado, desresponsabilizando-o da garantia dos direitos sociais, o governo aprofunda ainda mais os limites para a efetivação da "universalização" dos direitos. Em outras palavras, temos um avanço legal dos Direitos Humanos no mesmo momento em que se limita a plena viabilização da Constituição.

Buscando atender a reivindicação de movimentos da sociedade civil por ocasião da IV Conferência Nacional de Direitos Humanos, realizada em 13 e 14 de maio de 1999 na Câmara dos Deputados, em Brasília (BRASIL, 2002), no segundo governo FHC (1999-2002), o PNDH sofreu um processo de revisão, passando a destacar os direitos sociais e culturais no processo de "promoção e proteção dos direitos humanos".

Assim, o segundo PNDH (com período delimitado entre 2002 e 2007) buscou ampliar a esfera das ações governamentais com o objetivo de

[...] apoiar a formulação, a implementação e a avaliação de políticas e ações sociais para a redução das desigualdades econômicas, sociais e culturais existentes no país, visando à plena realização do direito ao desenvolvimento e conferindo prioridade às necessidades dos grupos socialmente vulneráveis (BRASIL, 2002). 
Cabe destacar que o segundo PNDH continuou em vigência no governo do presidente da República Luiz Inácio Lula da Silva. O PNDH II manteve a lógica de desresponsabilização do Estado e a agenda neoliberal foi incorporada como proposta de governo, efetivando, em nome do "crescimento econômico", um campo fértil para o mercado financeiro. Entretanto, seria um erro negar algumas diferenças que os dois Governos de Lula e, por último, o Governo Dilma construíram com relação aos dois governos de FHC. Distinto dos governos de FHC que realizou vários cortes de recursos para os programas sociais (NETTO, 1999), os Governos de Lula e o primei ro governo de Dilma Rousseff se focalizaram nas políticas compensatórias e seletivas (vide a implementação e o exacerbado crescimento do Programa Bolsa Família e a criação de novos programas sociais de mesmo cunho). Contudo, a experiência de institucionalização criada pelo governo de Fernando Henrique, que levou o governo federal a montar um verdadeiro Sistema Nacional de Direitos Humanos, criando espaços para sua própria fiscalização, e a maneira como eles foram transformados em um discurso oficial do Estado pela primeira vez no Brasil, foram ampliados e aprofundados pelos governos do Partido dos Trabalhadores (PT) através de uma institucionalização dos direitos humanos questionáveis, enquanto tal. Com força discursiva estatal ampliada e esvaziamento dos movimentos sociais, o PT consegue pautar as políticas sociais nas normas dos direitos humanos. No Plano Nacional de Direitos Humanos III de 2009 (BRASIL, 2009), o PT acrescentou novas questões, mas na realidade a ênfase à questão da segurança pública foi notória.

É importante mencionar que o paradigma bélico para a Segurança Pública é um artefato, uma construção política através da qual o capitalismo contemporâneo controla os excessos reais e imaginários dos contingentes humanos que não estão no fulcro do poder do capital financeiro. Para que essa construção política adquira o consentimento que necessita é fundamental naturalizar a barbárie. Essa naturalização da barbárie que temos assistido se dá no momento da história brasileira em que mais se avança, em termos legais, o debate dos direitos humanos, qual seja: o contexto neoliberal. Não por acaso esse avanço se dá isolado dos suportes necessários para sua efetivação. Em realidade, tais avanços engendraram ainda mais as ambiguidades e armadilhas do tema. O Brasil atinge nos governos do PT os mais altos níveis de encarceramento da história nacional.

Já no breve Governo Temer nada de diferente se cria, sendo no Governo Bolsonaro que o conservadorismo dos mencionados Canalhas, destacados por Trindade (2006), que disputam o tema dos Direitos Humanos, 
chegam ao poder. A partir daí, as criminalizações moralizantes se tornam mais fortes e perversas, sustentadas por fragmentos de discursos evangélicos, sem compromisso com a verdade. Em 2019, uma onda conservadora governamental sustenta as reformas ultraneoliberais do Governo de Bolsonaro, num contexto de barbarização das relações sociais.

\section{0 contexto da barbárie ultraneoliberal}

Podemos dizer que todas as ações governamentais dos governos (neo) liberais pós Constituição de 1988, e ultraneoliberais no pós-2016, só aprofundaram os limites para a efetivação da "universalização" dos direitos no Brasil.

Nos governos neoliberais observamos uma clara tendência de deslocamento das ações governamentais públicas - de abrangência universal no trato das necessidades sociais em favor de sua privatização.

Esse deslocamento da satisfação de necessidades da esfera do direito público para o direito privado ocorre em detrimento das lutas e de conquistas sociais e políticas extensivas a todos. É exatamente o legado de direitos conquistados nos últimos séculos que foram desmontados nos governos de orientação (neo)liberal, em uma nítida regressão da cidadania que tende a ser reduzida às dimensões civil e política, erodindo a cidadania social (IAMAMOTO, 2001, p. 75)

$\mathrm{Na}$ atualidade, a luta em defesa e pela garantia desses direitos se tornou um campo de tentativa de proteção e denúncia contra a situação de barbárie que vivemos.

Cabe ressaltar que não atribuímos ao termo barbárie o mesmo sentido que o discurso midiático reproduz, ou seja, referido exclusivamente às inseguranças das elites. Barbárie relaciona-se com as forças destrutivas acionadas em determinada sociedade para realização de projetos excludentes de civilização. A valorização do capital determina um crescente aumento de destruição, gerando um contingente populacional destituído de meios de sobrevivência e todas as consequências sociais originadas desta demanda.

Para Marx, o modo de produção burguês dependeria de crises periódicas para sobreviver, o que implica em regressões momentâneas de civilização. Assim, a relação entre crise no capitalismo e barbárie não é um fenômeno particular. A destruição das forças produtivas é uma necessidade 
cíclica do processo de valorização e acumulação do capital, como enunciado no Manifesto Comunista:

Nas crises evidencia-se uma epidemia social que teria parecido um contrassenso a todas as épocas anteriores - a epidemia de superprodução. A sociedade vê-se de repente reconduzida a um estado de momentânea barbárie; dir-se-ia que uma fome ou uma guerra de destruição generalizada lhe cortam todos os meios de subsistência; a indústria e o comércio parecem aniquilados. E por quê? Porque a sociedade possui civilização em excesso, meios de subsistência em excesso, indústria em excesso, comércio em excesso (MARX; ENGELS. 1998, p. 11-12)

Como registrou Menegat (2006, p. 33-34), a barbárie ganha funcionalidade no atual estágio de desenvolvimento do capitalismo. Desde 1929, busca-se driblar os momentos de forte crise econômica, diluindo seus efeitos de destruição no tempo. As crises agora se operam de maneira constante e em várias direções, elevando a sobrevivência à ideal de cidadania. 0 desemprego estrutural é a face mais visível desse processo, na medida em que priva milhões de pessoas do mercado de trabalho, sem perspectiva de retorno. 0 aumento do trabalho morto em razão do progresso tecnológico das indústrias faz com que outras formas de violência, para além da destruição das forças produtivas, sejam executadas. A administração do crescente exército industrial de reserva, cada vez com menor aspiração de integrar o "mundo do trabalho", depende da ampliação do sistema punitivo.

Convém lembrar que a compreensão do conservadorismo exige a aceitação da relevância da dimensão ideológica na configuração de um projeto político. Este reconhecimento exige que se entenda a ideologia como um recurso de poder fundamental ao esforço de articulação e de produção não só do que já existe, mas, sobretudo daquilo que se deseja realizar. Pressupõe que os homens, em cada momento histórico específico, diferenciados por interesses concretos, possuem diferentes interpretações e propostas para preservar ou alterar a realidade. Portanto, suas ações e percepções são fundamentais para compreender o processo histórico e seus resultados. Daí, como afirma Marilena Chauí, ser necessário reconhecer que,

[...] a ideologia não é sinônimo de subjetividade oposta à objetividade, não é preconceito nem pré-noção, mas é fato social justamente porque é produzida pelas relações sociais, possui razões muito determinantes para surgir e se conservar, não sendo um amontoado de ideias 
falsas que prejudicam a ciência, mas uma certa maneira de produção de ideias pela sociedade, ou melhor, por formas históricas determinadas das relações sociais (CHAUÍ, 1980, p. 31, grifo da autora).

Cabe ressaltar que o conservadorismo burkeano se particulariza pela defesa da moral tradicional e das hierarquias sociais contra a razão abstrata. Apesar da crítica, a matriz desse pensamento e ação naturaliza as desigualdades sociais produzidas pelo modo de produção capitalista.

Já o neoconservadorismo, como destaca Freire (2018), mantém o discurso moralizante e preconceituoso, mas busca sua legitimação mediante o discurso construído de repressão contra os trabalhadores ou pela criminalização dos movimentos sociais, dos pobres e da pobreza e da militarização da vida cotidiana. Como destacou Barroco (2003, p. 209),

[...] essas formas de repressão implicam violência contra o outro, e todas são mediadas moralmente, em diferentes graus, na medida em que se objetiva a negação do outro: quando o outro é discriminado lhe é negado o direito de existir como tal ou de existir com as suas diferenças.

É importante destacar que o ideário neoliberal, no campo da economia, em primeiro lugar coloca na pauta do dia a redução da tributação do capital, da regulamentação social da economia, cortando gastos públicos, privatização do grosso das atividades rentáveis e flexibilização das relações de trabalho. 0 mote é o Estado mínimo - ou Estado máximo para o Capital. Estas são suas propostas, como um receituário econômico para neoliberais.

Já os conservadores clássicos, que vem da linha de Burke, e passam pelo pensamento de Durkheim, não estão necessariamente afinados com a economia neoliberal. A inspiração atual vem da influência do neoconservadorismo americano, fortemente militarizado, sustentado ideologicamente pela religião protestante, que implementa uma política imperialista, operando mudanças internas na justificativa da política externa (FINGERUT, 2008).

A subalternidade de Bolsonaro a Trump deixa transparecer as mãos que pesaram no golpe de 2016. A defesa das armas durante a campanha e o apoio dos evangélicos já expressavam o antagonismo aos direitos humanos, avesso às armas e ao fundamentalismo religioso. Diferente dos Estados Unidos, onde o civismo ergue uma barreira contra as tentativas de supressão dos direitos civis, no Brasil o autoritarismo se expande extraindo do povo o pior: a intolerância, o preconceito, a violência, eivados de ódio. 
O neoconservadorismo que se apresenta no Brasil é irmão siamês da barbárie. 0 mesmo é a base de um ultraneoliberalismo, ainda mais perverso e incivilizado. Essa nova expressão define bem a pauta do atual governo.

\section{Neoconservadorismo e derrocada dos direitos huma- nos no Brasil}

Dificilmente o neoliberalismo poderia se tornar compatível com os direitos humanos. Essa combinação já sinalizava o acirramento das contradições sociais e de suas repercussões na política. A resistência a essa política se tornou o "lugar" das esquerdas durante os governos de FHC, Lula, Dilma, Temer e Bolsonaro. A distância entre as normas dos direitos humanos e os interesses neoliberais já anunciava a possibilidade de confronto. Restava aos governos saber como lidar com a questão, sem perder a legitimidade. Os governos petistas criaram mecanismo para enfrentar a questão. 0 Estado incorporou a participação social nos diversos conselhos de políticas, cujas normas estavam em conformidade com os direitos humanos. 0 controle social antes baseado na institucionalização, na burocratização e no autoritarismo deveria se transformar, passando a adotar as normas dos direitos humanos, tornando-se mais democrático, humanizado. Palavras como humanização, acolhimento, solidariedade, empatia, reconhecimento, foram se popularizando nos serviços públicos.

Porém, enquanto se pautavam as intervenções sobre diretrizes valorizadas pelos direitos humanos, as leis foram se tornando mais rigorosas e os governos mais violentos, ao mesmo tempo em que reduziam os investimentos nas políticas sociais. Desse modo, os direitos humanos iam se tornando inexequíveis ou muito limitados. 0 avanço do neoliberalismo acabou desacreditando os direitos humanos não apenas do ponto de vista ideológico, como também pelas limitações orçamentárias que lhes foram impostas.

Para que o campo da política pudesse ficar livre ao capital, destroçar os direitos humanos tornara-se fundamental. Não foi difícil encontrar nos neoconservadores, que já vinham em processo de crescimento na política, o apoio que faltava para esse objetivo. Desde 2006, o congresso tem observado a ação conjunta contra os direitos humanos de três importantes bancadas, conhecidas como BBB: bancada do boi (os ruralistas), da bíblia (os evangélicos) e da bala (representantes das forças de segurança pública, 
civis e militares). Essa associação constituiu o alicerce do golpe, a base do neoconservadorismo no Brasil.

O declínio dos direitos humanos, especialmente os direitos sociais, trabalhistas e ambientais, significava a destruição das barreiras que impunham limites ao capital. Em torno desse objetivo, todo esforço ideológico seria empregado e, para isso, foi necessário minar o espaço dos direitos humanos com uma moral religiosa apresentada como superior para toda a so ciedade.

Nestes termos, o ataque aos direitos humanos, na atualidade, não é meramente uma estratégia de governo, mas do capital. Neste sentido, a ressignificação dos direitos humanos pelo neoconservadorismo tem uma conotação que ultrapassa o governo Bolsonaro. A apropriação da religião, como elemento de integração social e veículo de propagação do empreendedorismo, favoreceu a imposição de uma ordem ultraneoliberal que favorece o enfraquecimento dos direitos humanos". Sob a aparência do cristianismo, o ultraneoliberalismo tem se afirmado sem medo de provocar grandes abalos à ordem.

Por conseguinte, os direitos humanos foram engolfados no neoconservadorismo e continuam perdendo campo diante dos apelos de uma moral cristã revigorada em tempos de crise do capital e de ajustes estruturais. Assim sendo, os ataques aos direitos humanos se constituem numa estratégia de dominação da política ultraneoliberal, que não conseguiu encontrar no liberalismo clássico e contemporâneo as bases da sua legitimação para implementar as reformas que desejavam.

Portanto, ilude-se quem pensa que o neoconservadorismo brasileiro emergiu de um processo incompleto de secularização do poder político. Ainda que o momento possa ser visto como a culminância de um processo que deita raízes na própria cultura brasileira, a questão da derrocada dos direitos humanos no Brasil dos dias atuais se liga primeiramente a uma questão da reprodução do capital no contexto de acumulação financeira em nível global, e não somente à figura de um presidente autoritário, rude e atrapalhado, que lança aos bastidores as decisões da política econômica, distraindo o público como arlequim do mercado financeiro.

Numa orquestração político-cultural, conservadores e liberais, apropriando-se das redes sociais e da mídia, principalmente da TV aberta, com diversos horários para os evangélicos e repórteres da violência, conseguiram transformar suas vítimas em bodes expiatórios, radicalizando a política, inaugurando uma disputa ideológica que acabou acusando os direitos 
humanos pelas violências sofridas cotidianamente na sociedade. (FREIRE; CARVALHO, 2008).

0 aprofundamento do medo é um elemento central neste contexto. As violências ajudam a construir um medo que aprofunda a forma de segregação e de aniquilamento de um inimigo ou um perigo, constituído pelas forças dominantes para se manterem no poder. Para Boldt, este tema é central no século XXI, pois

0 medo se tornou base de aceitação popular de medidas repressivas penais inconstitucionais, uma vez que a sensação de medo possibilita a justificação de práticas contrárias aos direitos e liberdades individuais, desde que mitiguem as causas do próprio medo (BOLDT, 2013, p.96).

0 medo faz parte de experiências sociais que se inter-relacionam com o processo de institucionalização, que rege a vida em sociedade (SOUSA-FILHO, 1995).

Colocando-se como "homens de bem", "agentes incorruptíveis", "religiosos", "cristão", "senhores de família", os "neocons" do Brasil criaram em torno de si a imagem do correto, estampando um moralismo de fachada. Como se não fosse o bastante, a ideologia religiosa cristã passou a ser a referência para o desmantelando dos direitos humanos, a base do Estado Democrático de Direitos.

Tal fato permitiu que o ultraneoliberalismo avançasse na derruição de toda a construção dos direitos humanos, com a finalidade de tornar a economia mais flexível aos interesses do capital, reproduzido com o mínimo de políticas sociais. Neste processo de desinstitucionalização do controle social, o território adquire centralidade, e passa a ser socialmente diagnosticado, recebendo uma avaliação em termos de possibilidade de intervenção social. Por outro lado, as medidas de controle sobre as famílias acabaram transpondo a "questão social" ao privado, trazendo a "problemática do espaço doméstico" como o lugar da violação de direitos, como se pouco ou quase nenhuma relação tivesse com a questão da ordem pública.

Por conseguinte, a naturalização dos crimes acentuou o desejo de vingança, obnubilando as críticas direcionadas à ordem. Todas as vezes em que a mídia se indignou contra os crimes sexuais contra crianças, o foco se concentrou sobre o sujeito praticante. Jamais se questionou a construção dessa sociedade capaz de cometer tais crimes. Porém, a ênfase na punição não tem sido suficiente para interrompê-los, e as restrições orçamentárias não têm permitido que as ações de prevenção ultrapassem o código penal. 
Violência urbana e violência doméstica passam a impressão de que o mal está em toda parte, e a sociedade passa por uma crise de valores, sofrendo com a sua decadência moral. Essa interpretação tão divulgada na mídia, num contexto de abandono do discurso das desigualdades de classe, foi a brecha para o revigoramento do neoconservadorismo político.

No discurso salvacionista do resgate de valores, os "neocons" respaldam os interesses do capital e compensam a fraca legitimidade do Estado com o aumento da repressão contra os escolhidos como "inimigos da ordem" - os pobres, a esquerda e os defensores dos direitos humanos. A ordem militarizada é disfarçada no verniz do cristianismo, com a justificativa de que toda a força pode (e deve) ser empregada contra o mal que ameaça a paz social. A política torna-se então um trabalho do "bem contra o mal". Nesse raciocínio, o governo Bolsonaro instaura um Estado inimigo dos direitos humanos, mas que não chega a romper com a democracia, ainda que reivindique o tempo todo para si o espaço de autonomia da política.

Neste contexto, as resistências existem e se constroem na disputa de projetos societários. A divisão da sociedade ficou nítida com o golpe de 2016 que destituiu a presidente Dilma Roussef e mostrou claramente os projetos políticos em disputa através da reação da chamada "elite do atraso", tão bem analisada por Jessé de Souza (2017).

0 decorrer do processo político acabou expondo o caráter conservador e classista do golpe. A referência aos direitos humanos, fraca para disciplinar o Estado e as elites mencionadas, tornou-se alvo da nova forma de fazer política. Críticas, desrespeito, retrocessos e omissão se acentuaram neste contexto.

Não obstante, os direitos humanos não foram destruídos como um todo. Como modalidade de intervenção social, permanece uma referência para a proteção de grupos que sofrem com a violência imposta por outros grupos ou indivíduos. Porém, este modo de operacionalização tornou-se ainda mais arriscado, pois conferiu à política um sentido judiciário, fundamentalmente punitivo e insuficiente para garantir proteção às vítimas. Além disso, os direitos humanos, desde a crítica da biopolítica, têm se concentrado sobre o problema das relações sociais, deixando submersa a questão das desigualdades de classe e da extremada concentração de riquezas.

0 debate que posiciona classe de modo separado das identidades sociais, reivindicando a superioridade destas últimas, subordina o econômico ao cultural, capturando os direitos humanos aos fios da grande teia da direita. Transformar a luta de classes numa disputa cultural, pelo reconhecimento dos direitos de grupos minoritários contra os detentores do capi- 
tal, foi uma estratégia que acabou esvaziando as pautas igualitárias, lançando os direitos humanos na "cilada da diferença". Essa expressão foi empregada por Pierucci (1999) para lembrar que a diferença é um tema das tradições da direita, podendo, portanto, se converter numa razão para se dirigir contrariamente aos movimentos de esquerda. Ou seja, a esquerda, por se inclinar ao debate das identidades sociais, tomaria para si as "armas" do conservadorismo, que sempre negou as implicações das desigualdades de classe, destacando a importância das tradições na formação das identidades sociais.

Por sua vez, o esmorecimento das lutas pela igualdade emergiu no contexto do avanço da agenda neoliberal no país. As lutas por reconhecimento sobrepuseram as disputas por justiça social, travadas contra a concentração do capital. A matriz da inclusão social e da ampliação das oportunidades sociais se generalizou, e os programas de transferência de renda se tornaram praticamente uma unanimidade na política, sobretudo a partir dos governos do PT.

De certo modo, este não é um fenômeno particular do Brasil. Com o desmoronamento do bloco socialista, as esquerdas mudaram, mas a direita permaneceu sendo o que sempre foi. Segundo Pierucci (1999), as esquerdas passaram a adotar o discurso das diferenças, há mais de duzentos anos defendido pelos conservadores:

O pavilhão da defesa das diferenças, hoje empunhado à esquerda com ares de recém-chegada inocência pelos "novos" movimentos sociais (o das mulheres, o dos negros, dos índios, o dos homossexuais, o das minorias étnicas ou linguísticas ou regionais etc.), foi na origem - e permanece fundamentalmente - o grande desígnio das direitas velhas ou novas, extremas ou moderadas. Pois, funcionando no registro da evidência, as diferenças explicam as desigualdades de fato e reclamam a desigualdade (legítima) de direito. Difference oblige, chacun à sa place (PIERUCCI, 1999, p. 19, grifos do autor).

Ao fazer da luta política uma disputa contra as representações sociais que geram discriminações e subalternidades, as esquerdas abriram a brecha para o neoconservadorismo se afirmar no jogo político cultural. Nada impedia então que, nesse nível, a questão emergisse como um problema de afirmação do político-religioso, como assistimos nos dias atuais.

Desde sempre a direita exerce a sua dominação, combinando o econômico e o cultural. A identificação das representações sociais como instrumento de sujeição também não é nova na teoria social. Elas estão presentes 
no pensamento dos teóricos marxistas da dependência, assim como em outros autores não marxistas da sociologia brasileira como Guerreiro Ramos. Portanto, o tema não escapava a interpretação das singularidades nacionais da relação entre classe e raça, ainda que enviesado pelas controvérsias da época. $\mathrm{O}$ avanço desse debate tem sido importante, não se nega isso, porém "se é para alguém de esquerda abraçar a diferença, que o faça sem abrir mão da igualdade" (PIERUCCI, 1999, p. 31).

Ademais, não só as diferenças, mas também a maneira de lidar com elas pode ser um tanto problemática. Assim tem acontecido com o discurso do empoderamento que sinaliza para saídas individuais, decorrentes de mudanças de postura, mediante a mobilização de recursos psicossociais e jurídicos. Essas inciativas individualizadas têm sido a outra face da moeda diante da desigualdade econômica. Sem se reportar a estrutura de desigualdade, o sujeito é levado a tirar forças de si mesmo, porém as expropriações continuam avançando, e nem mesmo se pode garantir a redução da discriminação.

Portanto, se por um lado cresce a consciência acerca das formas de violação de direitos que se desenvolvem nos múltiplos espaços da vida humana, por outro as lutas coletivas contra a expropriação de direitos parecem causar menos indignação. Talvez por isso, o esforço de empregar o direito para mudar comportamentos, num trabalho de coerção e punição, tenha alcançado o fortalecimento do sentimento de justiça como vingança. Por efeito, o punitivismo se acentua, apesar dos resultados pífios em termos do que se espera alcançar a partir das mudanças no Código Penal. Mesmo parecendo um caminho sem volta, estas iniciativas expressam, sobretudo, o embaralhamento das propostas de direita e esquerda que têm lançado os direitos humanos no centro das contradições do capitalismo nos dias atuais.

\section{Considerações finais}

A crítica aos direitos humanos acelerou o processo de naturalização da violência, transformou o trabalho em servidão e promoveu o desmantelamento da proteção social iniciado com as medidas neoliberais e que está se completando com o neoconservadorismo. A expressão máxima deste fenômeno político foi a chegada ao poder - em 2019 - de uma figura que representa tudo que é contrário aos direitos humanos.

Compreendidos como barreira à acumulação do capital, os direitos humanos, no Brasil, têm sido minados pelas representações religiosas que 
estrategicamente impregnaram o ambiente da política. Apontados pelos neoconservadores como o motivo de todos os males, sob acusação de defender o socialismo, autorizar a prostituição, o aborto e o casamento entre casais do mesmo sexo, os direitos humanos foram sendo rechaçados, ficando circunscritos aos grupos mobilizados pela sua defesa, em sua maioria organizados a partir da fragmentação da luta de classes. Portanto, cada vez mais distanciados da possibilidade histórica de construção de uma ação coletiva das classes e camadas subalternizadas pelo capital.

Cabe lembrar que este processo foi avançando enquanto as esquerdas se tornavam mais voltadas à crítica das representações culturais do que das desigualdades de classe. Os movimentos por direitos humanos, ao lutarem por mudanças na superestrutura, sem conferir a devida atenção aos processos de transformação gerados na infraestrutura, negligenciaram a totalidade e por isso foram surpreendidos pela reação neoconservadora.

A aproximação dos movimentos de direitos humanos com a direita ocorreu no processo de institucionalização em que tais movimentos sociais foram avançando sobre os espaços no Estado, travando uma luta contra as representações autoritárias das políticas que produziam a submissão de grupos minoritários, sobrepondo o cultural ao econômico, com objetivo de transformação nas regras de acesso às políticas sociais, na tentativa da ampliação das chamadas oportunidades sociais. Desse modo, a disputa por recursos de poder foi se sobrepondo às reinvindicações por igualdade econômica. Contudo, a valorização desses direitos não se restringe a cultura ou a formação da consciência. Trata-se de uma questão objetiva: o direito mais (neo)liberal é menos humano.

Os tempos atuais têm demonstrado que a defesa e o exercício dos direitos humanos se tornaram algo cada vez mais criminalizado e aviltado.

Sem ignorarmos a complexidade do debate sobre os direitos humanos apontadas por Trindade (2006), Slavoj Zizek (2010) dentre outros, e muito antes já registrada por Marx, ao analisar os limites de seus postulados irrealizáveis plenamente na sociedade do capital, nos parece fora de dúvidas que o debate, a defesa e a ativa intervenção no campo dos direitos humanos assinalam avanços civilizatórios extremamente importantes, ainda que muito desiguais, que precisam de lutas diárias para a sua manutenção e novas conquistas. Como observou Mészáros,

Enquanto estivermos onde estamos, e enquanto o "livre desenvolvimento das individualidades" estiver tão distante de nós como está, a 
realização dos direitos humanos é e permanece uma questão de relevância para todos os socialistas (MÉSZÁROS, 1993, p. 217).

\section{Referências}

ALMEIDA, S. S. de. Violência e Direitos Humanos no Brasil. In: Revista Praia Vermelha. Ética e Direitos Humanos. v. 11, n. 1, Rio de Janeiro, UFRJ, PPGESS, p. 40-66. Set. 2004.

ANDRADE, C. D. Nosso tempo. In: A rosa do povo. Rio de Janeiro: Record, 2000, p. 29-37.

BARROCO, M. L. S. Direitos Humanos e Desigualdade. In: As novas faces da barbárie capitalista: desigualdade se combate com direitos. (Conferências e deliberações do 31ํㅡㄹ Encontro Nacional CFESS/CRESS). Brasília, CFESS, 2003. $\mathrm{n} / \mathrm{p}$.

BOLDT, R. Criminologia midiática: do discurso punitivo à corrosão simbólica do garantismo. Curitiba: Juruá Editora, 2013.

BRASIL. Lei n. 6.683/79, de 28 de agosto de 1979. Concede anistia e dá outras providências. Diário Oficial [da]

República Federativa do Brasil, Poder Executivo, Brasília, DF, 28 ago. 1979. Disponível em: <http://www.planalto.gov.br/ccivil_03/ leis/L6683.htm>. Acesso em: 20 jul. 2019.

. Lei n. 9140/95, de 4 de dezembro de 1995. Reconhece como mortas pessoas desaparecidas em razão de participação, ou acusação de participação, em atividades políticas, no período de 2 de setembro de 1961 a 15 de agosto de 1979. Diário Oficial [da]

República Federativa do Brasil, Poder Executivo, Brasília, DF, 4 dez. 1995. Disponível em: <http://www.planalto.gov.br/ccivil_03/ leis/19140.htm>. Acesso em: 15 maio 2019.

Ministério da Justiça. Programa Nacional De Direitos Humanos. Governo Federal. Fernando Henrique Cardoso - Brasília / Presidência da República. Secretaria de Comunicação Social. Ministério da Justiça, 1996. Disponível em: <http://www.biblioteca.presidencia.gov.br/publicacoesoficiais/catalogo/fhc/programa-nacional-de-direitos-humanos1996.pdf>. Acesso em: 27 set. 2020.

Ministério da Justiça. Programa Nacional De Direitos Humanos II. Governo Federal / Secretaria de Estado de Direitos Humanos, 2002, Dispo- 
nível em: <http://www.dhnet.org.br/dados/pp/pndh/pndh_concluido/index.html>. Acesso em: 16 nov. 2010.

BRASIL. Programa Nacional de Direitos Humanos III. Governo Federal / Secretaria de Estado de Direitos Humanos, 2009, Disponível em: <http:// www.dhnet.org.br/dados/pp/a_pdf/ pndh3_programa_nacional_direitos_humanos_3.pdf>. Acesso em: 20 ago. 2020.

CHAUÍ, M. 0 que é ideologia? Coleção Primeiros Passos. Editora Brasiliense: São Paulo, 1980.

. Direitos humanos e medo. In: FESTER, A.C.R. (org.). Direitos Humanos. São Paulo: Brasiliense, 1989, p. 15-36.

FREIRE, S. de M. Mídia, Violência e Questão Social: a pedagogia do capital. In: __ ( org.). Direitos Humanos e Questão Social na América Latina. Rio de Janeiro: Editora Gramma, 2009. p. 171-198.

Cultura Política, “questão social” e Ditadura Militar no Brasil: o simulacro do pensamento político de militares e tecnocratas no pós-1964, RJ: Ed. Gramma, 2011.

. (org.). Direitos Humanos Para Quem? Contextos, Contradições e Consensos. Rio de Janeiro: Editora Gramma, 2014.

. Direitos humanos no Brasil: aportes para compreensão das ambiguidades e armadilhas persistentes. Em Pauta, Revista da Faculdade de Serviço Social da Universidade do Estado do Rio de Janeiro. v. 12, n. 34, Rio de Janeiro, FSS/UERJ, p. 71- 89, 2. sem. 2014.

. A instrumentalidade dos conservadorismos no atual contexto de hegemonia do capital. In: Politics, Democracy and New Global Authoritarianism . Quadranti - Rivista Internazionale di Filosofia Contemporanea. v. VI, n. 2, pubblicata dalle Edizioni il Sapere srl.: Roma, p.189-212, 2018.

Cultura Política e Revolução Burguesa no Brasil: a instrumentalidade do pensamento autoritário. Rio de Janeiro: Editora Gramma, 2020.

.; CARVALHO, Andreia. Midiatização da Violência: os labirintos da construção do consenso. Revista Eletrônica Textos e Contextos, v.7, n.1, p. 151-164, jan. /jun. 2008.

FINGERUT, A. A influência do pensamento neoconservador na política externa de George W. Bush. 2008, 150f. Dissertação (mestrado em Ciên- 
cias Sociais), Faculdade de Ciências e Letras da Universidade Estadual Paulista Júlio de Mesquita Filho, Araraquara, 2008. Disponível em: <http:// hdl.handle.net/11449/98996>. Acesso em: 20 set. 2020.

GONZÁLEZ, R. S. Direitos Humanos na América Latina Hoje: heranças de Transições Inconclusas (ano 2007). In: Site do Fórum de Entidades de Direitos Humanos. Disponível em: < http://www.direitos.org.br/ >. Acesso em 23 abr. 2010.

IAMAMOTO, M. V. Trabalho e indivíduo social: um estudo sobre a condição operária na agroindústria canavieira paulista. São Paulo: Cortez, 2001. MARX, K.; ENGELS, F. Manifesto do Partido Comunista, São Paulo: Cortez, 1998.

MENEGAT, M. 0 olho da barbárie. São Paulo: Expressão Popular, 2006. MÉSZÁROS, I. “Marxismo e Direitos Humanos” In: Filosofia, Ideologia e Ciência Social: ensaios de negação e afirmação. São Paulo: Ensaio, 1993. p. 87-92.

NETTO, J. P. FHC e a política social: um desastre para as massas trabalhadoras. In: LESBAUPIN, Ivo (org.). 0 desmonte da nação: balanço do governo FHC . Petrópolis, RJ: Vozes, 1999. p. 167-189

ONU-BRASIL - Declaração Universal Dos Direitos Do Homem. Trad. Centro de Informação das Nações Unidas no Brasil, UNIC/Rio/005, Dezembro de 2000 (DPI/876)

PIERUCCI, A. F. Ciladas da Diferença. São Paulo: Curso de Pós-graduação em Sociologia da USP/Ed 34, 1999.

SILVA. J. A. da. Curso de Direito Constitucional Positivo. 26. ed. São Paulo: Malheiros, 2006.

SOUSA-FILHO, A. de. Medos, mitos e castigos: notas sobre a pena de morte. São Paulo: Cortez, 1995.

SOUZA. J. A Elite do Atraso. Da Escravidão à Lava Jato. Rio de Janeiro: Leya, 2017.

TRINDADE, J. D. de L. História social dos direitos humanos. 2. ed. Editora Petrópolis: São Paulo, 2006.

ZIZEK, S. Contra os Direitos Humanos. In: Mediações, Londrina, Dossie: Direitos Huamnos-Diversos Olhares. v.15, n.1, p.11-29, jan/jun. 2010. 